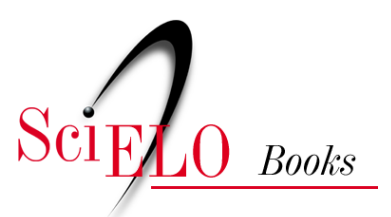

\title{
A política e a capoeira regional
}

\author{
Hellio Campos
}

\section{SciELO Books / SciELO Livros / SciELO Libros}

CAMPOS, H. A política e a capoeira regional. In: Capoeira regional: a escola de Mestre Bimba [online]. Salvador: EDUFBA, pp. 80-84. ISBN 978-85-232-1727-3. Available from: doi: 10.7476/9788523217273.0009. Also available in ePUB from: http://books.scielo.org/id/p65hq/epub/campos-9788523217273.epub.

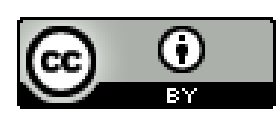

All the contents of this work, except where otherwise noted, is licensed under a Creative Commons Attribution $\underline{4.0 \text { International license. }}$

Todo o conteúdo deste trabalho, exceto quando houver ressalva, é publicado sob a licença Creative Commons Atribição 4.0. 


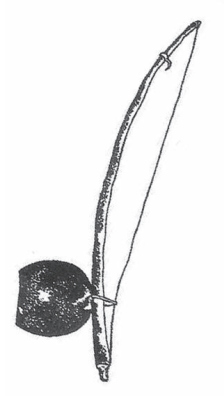

A política e a capoeira regional

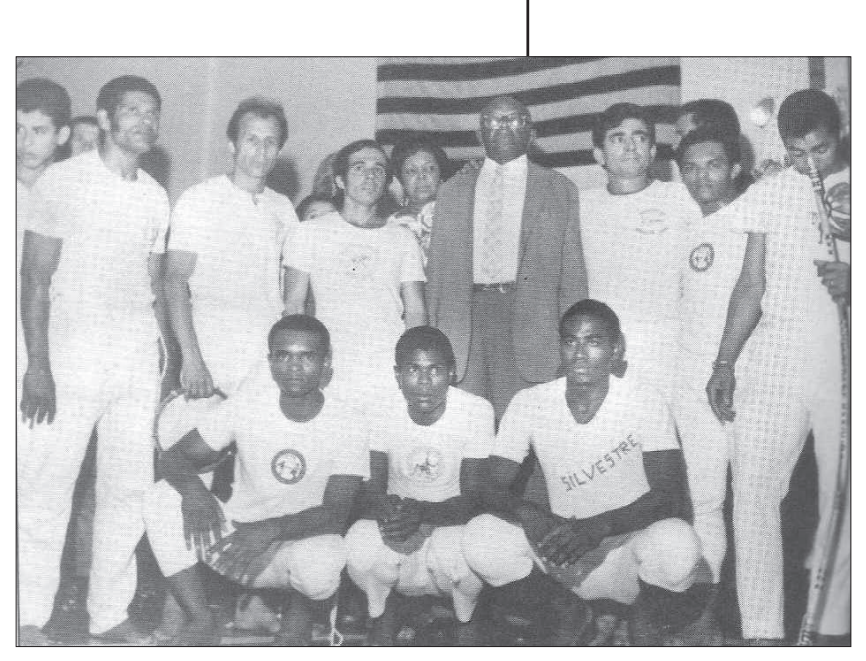


Wos últimos dez anos, temos acompanhado e observado que o foco da pesquisa sobre a capoeira tem tomado novos rumos. Já existem pesquisadores interessados em aprofundar suas investigações no âmbito das questões educativas, culturais, sociais, esportivas, técnicas, bem como na relação entre a capoeira e a Educação Física e, mais recentemente, em sua articulação com a promoção da saúde. Este fato nos parece bastante saudável, pois mostra uma gama de interesses e conhecimentos bem diversificados, tentando compreender a capoeira de maneira global, valorizando, assim, todos os seus segmentos. No entanto, o tema "política" tem sido muito pouco explorado no universo da capoeira.

Três autores chamam nossa atenção para as questões políticas da Capoeira Regional: o primeiro, Frederico José de Abreu, no seu livro "Bimba é bamba: a capoeira no ringue" (1999), aborda de maneira singular o momento da criação e da expansão da Capoeira Regional na década de 1930 e ressalta a afigura de Mestre Bimba como um regente, mostrando ser ele um líder e detentor do poder.

O segundo, Luiz Renato Viera, escreveu "O jogo da capoeira: cultura popular no Brasil" (1995), livro que é fruto de sua dissertação de mestrado, apresentada ao Departamento de Sociologia, da Universidade de Brasília, e enfoca a capoeira no período de 1930 a 1945, destacando a relação das manifestações culturais do negro e a política da era Vargas, através do estudo das transformações ocorridas no âmbito ritual e gestual da capoeira.

O terceiro autor, Antônio Liberac Cardoso Simões Pires, produziu "Bimba, Pastinha e Besouro Mangagá" (2002), parte de um trabalho maior, especificamente, de sua tese de doutoramento "Movimentos da cultura afro-brasileira: a formação histórica da capoeira contemporânea (1890-1950)". O livro trata basicamente da biografia dos três mestres da capoeira baiana.

Muito se tem discutido sobre a relação de Mestre Bimba com a política, sua estratégia para a divulgação e a promoção da Capoeira Regional, sua conduta frente ao populismo de Vargas e sobre o embranquecimento da capoeira. Para Reis, os dois expoentes da capoeira na Bahia tinham condutas políticas diferentes diante da arte de capoeirar: Mestre Pastinha tinha como foco legitimar a capoeira como uma prática africana, diferenciando-a da "mestiçagem" da Capoeira Regional, praticada por Mestre Bimba (1997, p. 99).

Entendemos como "mestiçagem" o fato dos alunos brancos da Faculdade de Medicina terem ido aprender e praticar a capoeira no Centro de Cultura Física Regional, onde, tam- 
bém, aprendiam os negros e mulatos. Decanio, estudante de medicina e aluno de Mestre Bimba, assim fala sobre o branqueamento da Capoeira Regional, citando que Cisnando ${ }^{1}$ "foi o primeiro aluno branco da classe social dominante em Salvador" (1996, p. 111). Para Campos, a aproximação da Faculdade de Medicina do CCFR favoreceu, de maneira marcante, a integração de Bimba com os estudantes de medicina (2001, p. 168).

Sobre Mestre Bimba e suas conquistas políticas, Vieira afirma que "Bimba operou o início do contato da capoeira com outras esferas sociais, além da periferia das grandes cidades, recodificando os rituais nos moldes do ambiente político da época" (1995, p. 130).

Bimba demonstra ser arrojado no seu intento de divulgar a Capoeira Regional para todos os segmentos da sociedade: realiza desafios e sobe ao ringue para enfrentar os principais lutadores da época; viaja com seu grupo de capoeiristas para outros Estados - São Paulo e Rio de Janeiro - onde realiza diversas competições e apresentações; desfila e apresenta seus capoeiristas na data magna da Bahia, o Dois de Julho; ministra aulas na Polícia Militar e no Exército Brasileiro; funda uma academia; apresenta-se no Palácio da Aclamação para o Presidente da República, Getúlio Vargas, e o Governador da Bahia, Dr. Régis Pacheco; e torna-se uma pessoa presente na imprensa falada e escrita.

Muniz Sodré reafirma a obstinação de Mestre Bimba, relatando que "Bimba jamais deixou de praticar e de tentar mostrá-la em público. Tanto que, em 1918, fez uma vaquinha entre seus discípulos para juntar sete tostões, preço de uma licença especial da polícia para uma hora de demonstração do jogo" (2002, p. 52).

Abreu assim se refere ao Mestre Bimba e à sua relação com a sociedade e o poder constituído:

Contrariando as expectativas da sociedade em relação ao negro, Bimba se impóe perante ela, como capoeirista, mestre de um ofício negro socialmente rejeitado. Sua atitude pessoal teve consequência histórica de ordem coletiva: ao projetar-se socialmente projetou seu ofício "tirei a capoeira de debaixo do pé do boi". Na transação de Bimba com o poder político, o esquema de capangagem estava fora de cogitação: a sua personalidade não coincidia com o estereótipo do capoeirista desordeiro que a Repressão já sabia como lidar e o poder político cooptar. É possível que por trás do convite para a capoeira se apresentar no palácio estivesse uma forma sutil de apresentá-la como resíduo exótico e pitoresco de "nossa herança cultural..." (1999, p. 26-33).

Ao criar a Capoeira Regional, Mestre Bimba estabelece uma ruptura com a capoeira praticada e, destacando-se entre os demais capoeiristas da época, passa a exercer uma liderança: é enaltecido como ídolo popular, confirma o respeito nas rodas de capoeira, nas desavenças com a polícia e na maestria no ensino de sua arte. Para alguns autores este acontecimento é destacado como um rito de passagem: Vieira diz ser Mestre Bimba "um agente de mudança" (1996, p. 135); Muniz Sodré afirma ser Mestre Bimba "uma das últimas grandes figuras do que se poderia chamar de ciclo heróico dos negros da Bahia" (2002, p. 11); e Reis considera Mestre Bimba "um dos heróis culturais da capoeira brasileira" (1997, p. 97), resgatando ainda o registro do Centro de Cultura Física Regional, em 1937, na Secretaria de Educação, Saúde e Assistência Pública da Bahia.

Figura 2 Mestre Bimba sendo cumprimentado pelo Presidente Getúlio Vargas, em Salvador (1953). 


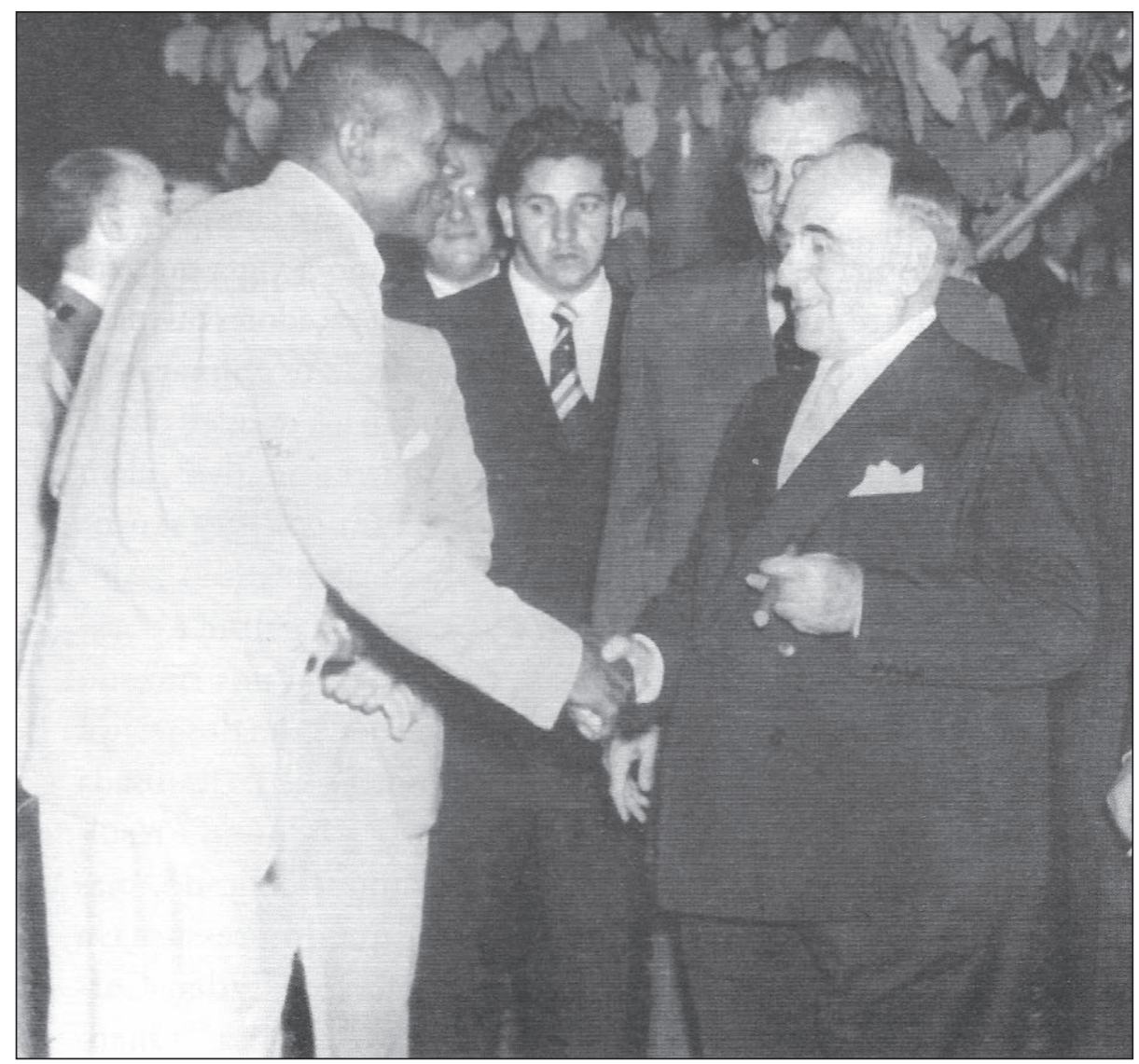

Mestre Atenilo, em entrevista a Mestre Itapoan (1991) publicada na obra "Mestre Atenilo: o 'relâmpago' da Capoeira Regional", afirma que Mestre Bimba exercia o poder através de sua liderança junto aos capoeiristas. Narra o fato de que Bimba reuniu todos os capoeiristas no Bogum, fim de linha do Engenho Velho de Brotas, e anunciou o seu desejo de mudar da Capoeira Angola para a Capoeira Regional, dizendo que, em breve, as pessoas estariam caçoando dos capoeiristas que estariam levando tapa na rua. E enfatiza, ainda, que Bimba "chegava junto", exigia obediência.

Almeida assim confere:

Itapoan ele dizia: "olha Itapoan, não fiquei rico porque fui muito burro. Qualquer coisa eu metia a mão, dava esporro e mandava embora. Fosse quem fosse...".

Atenilo ele queria era que obedecesse a ele. Quando ele chegava em uma roda assim, não precisava dizer nada. Ele olhava assim, a turma já sabia quem ele era, não precisava dizer nada, pronto (1991, p. 11).

A relação entre política e poder é bem caracterizada por Bobbio, Matteucci \& Pasquino: "o conceito de Política, entendida como forma de atividade ou de práxis humana, está estreitamente ligada ao poder" (1992, p. 955). E poder é definido pela relação entre dois sujeitos, quando um impõe ao outro a sua vontade, determinando o seu comportamento. É uma forma de imposição no sentido de obter "qualquer vantagem" ou "efeitos desejados". 
Para Decanio ${ }^{2}$ - aluno de Mestre Bimba da década de 1930 - "ele exercia o poder, ele era a Capoeira Regional". Estas palavras reforçam o que diz Itapoan e Atenilo sobre a personalidade e o jeito de comandar de Mestre Bimba.

Essa inquietação de Bimba em perseguir o seu objetivo é algo notável, se considerarmos que era um homem negro e sem estudo, quase analfabeto, porém astuto, corajoso, destemido, determinado, vivido e dotado de uma sabedoria toda peculiar, adquirida nas ruas, rodas de capoeira e rodas da vida. Era um líder na expressão pura da palavra.

${ }^{1}$ José Cisnando Lima, nasceu em 9 de outubro de 1914 no Sítio Santa Rosa, Crato/CE. Médico formado pela Faculdade de Medicina da Bahia em 1932.

${ }^{2}$ Comunicação Pessoal, em outubro de 2002. 